\title{
High cycle fatigue assessment of steel load-carrying cruciform welded joints: an overview of recent results
}

\author{
Wei Song, Xuesong Liu \\ State Key Laboratory of Advanced Welding and Joining, Harbin Institute of Technology, Harbin 150001, China. \\ swingways@hotmail.com, liuxuesong@bit.edu.cn
}

\begin{abstract}
In this paper, high cycle fatigue failure behavior of steel Loadcarrying Cruciform Welded Joints (LCWJ) is assessed by means of local approaches. Different analytical solutions for weld toe and weld root are extended and applied to illustrate the effects of LCWJ geometry under cycle tension and bending based on Notch Stress Intensity Factors (NSIFs). The extended analytical solutions are validated by comparing finite element data from several simulations in terms of LCWJ models, resulting in a good agreement. A bulk of experimental data taken from tests and the literature is calculated by the proposed solutions as the forms of SED, NSIF and Peak Stress Method (PSM). The results show that the NSIF-based analytical solutions for steel LCWJ are effective for high cycle fatigue failure analyses.
\end{abstract}

KEYWORDS. Analytical solutions; Strain energy density; Load-carrying cruciform joints; Tension and bending.

\section{open Access}

Citation: Song, W., Liu, X., High cycle fatigue assessment of steel load-carrying cruciform welded joints: an overview of recent results, Frattura ed Integrità Strutturale, 46 (2018) 94101.

Received: 24.04 .2018

Accepted: 06.07.2018

Published: 01.10 .2018

Copyright: (C) 2018 This is an open access article under the terms of the CC-BY 4.0, which permits unrestricted use, distribution, and reproduction in any medium, provided the original author and source are credited.

\section{INTRODUCTION}

A $\mathrm{s}$ one of the most typical connection types in shipbuilding or ocean engineering structures, the Load-carrying Cruciform Welded Joints (LCWJ) is widely used. Numerous advanced local approaches have been proposed to characterize the fatigue life of welded joints, such as notch stress [1], hot spot stress [2], equivalent structural stress method [3], NSIF method [4, 5], SED method [6-10], PSM [11, 12], fracture mechanics method [13], and other method [14]. Due to large numbers of complicated FE models are required to be created, it is cumbersome and time-consuming process for serving the needed results. To simplify this procedure of creating models, an analytical formulation based on NSIFs is extended to calculate the fatigue life indicator of local approaches considering different joints geometry and cyclic loading modes.

The fatigue life of the weld toe failure in LCWJ tends to take longer than weld root failure due to the discrepancy of crack locations. Zong et. al [15] discussed the effects of initial crack size and crack mode fatigue performance in LCWJ by fracture mechanics approach. In addition, Singh et. al [16] investigated the high cycle fatigue life variation of AISI 304L steel LCWJ considering lack of penetration sizes. Effective Traction Stress (ETS) and Equivalent Effective Traction Stress (EETS), which were based on structural mechanics theory, were employed to illustrate the weld toe and weld root failures as fillet 
weld size varies by Xing [17]. From another perspective, NSIFs are adequate to precisely assess the fatigue crack initiation at sharp corner notches or crack-liked notches [18]. However, the process is computationally expensive and highly impractical for complex component geometries and/or long loading histories. Recently, Qian et al. [19] and Saiprasertkit et al. [20] provided explicit parametric expressions for non-load-carrying fillet welded joints and LCWJ considering different loading conditions and material properties based on a fictitious notch rounding concept. Hence, these analytical researches give us some inspiration to extend corresponding functions. SED values can be expressed as a function of relevant SIFs, which are estimated readily by analytical equations.

In this paper, the primary goal is to assess fatigue life of LCWJ by extending an analytical formulation from the NSIFs including weld toe and weld root in LCWJ. Then, SED and PSM values are used to characterize the fatigue life from the related analytical equations. Such simple analytical equations allow a direct estimation of NSIF, SED and PSM values at weld toe or weld root in LCWJ by the available experimental data from fatigue tests and literature.

\section{NOTCH MECHANICS THEORY}

he problem of singularity at sharp notch tip has been solved by Williams solutions for mode I and mode II loading. Lately, these Williams solutions were introduced into NSIFs, to characterize quantitively the intensity of the asymptotic stress distributions close to a notch tip using a polar coordinate system (r, $\theta)$. NSIFs related to Mode I and II can be expressed by the notch stress fields, which are defined as follow equations [21]:

$$
\begin{aligned}
& K_{1}^{N}=\sqrt{2 \pi} \lim _{r \rightarrow 0^{+}} r^{1-\lambda_{1}} \sigma_{\theta \theta}(r, \theta=0) \\
& K_{2}^{N}=\sqrt{2 \pi} \lim _{r \rightarrow 0^{+}} r^{1-\lambda_{2}} \tau_{r \theta}(r, \theta=0)
\end{aligned}
$$

where the stress components $\sigma_{\theta \theta}$ and $\sigma_{r \theta}$ have to be evaluated along the notch bisector $(\theta=0)$.

Since the mesh strategy limits the developing of the NSIF method for complicated structures. We can obtain the notch intensity conveniently and avoid the disadvantage of NSIF method that their units are not uniform for different notch angle. Under plane strain conditions, the SED solutions containing mode I and mode II can be expressed by Eqn. (3) over a semicircular sector in Fig. 1 [22].

$$
\Delta \bar{W}=\frac{e_{1}}{E}\left[\frac{\Delta K_{1}^{N}}{R_{c}^{1-\lambda_{1}}}\right]^{2}+\frac{e_{2}}{E}\left[\frac{\Delta K_{2}^{N}}{R_{c}^{1-\lambda_{2}}}\right]^{2}
$$

where $\mathrm{E}$ is the Young's modulus, and $R_{c}$ is the radius of the semicircular sector, which is dependent on the material properties. It is defined as $R_{c}=0.28 \mathrm{~mm}$ for steel welded joints. The parameters $e_{1}, e_{2}$ are dependent on the opening angle $2 \alpha$ and on the Poisson's ratio $v$. Lazzarin defined following convenient functions to assess the high cycle fatigue of welded joints for two fracture modes by simplifying the expression of NSIFs:

$$
\begin{aligned}
& \Delta K_{1}^{N}=k_{1} \Delta \sigma_{n} t^{1-\lambda_{1}} \\
& \Delta K_{2}^{N}=k_{2} \Delta \sigma_{n} t^{1-\lambda_{2}}
\end{aligned}
$$

where $\Delta \sigma_{n}$ is the range of the nominal stress, $t$ is the plate thickness and $k_{i}$ are non-dimensional coefficients, which are dependent on the overall joint geometry and on the kind of remote applied load (membrane or bending). Therefore, the SED equation can be modified by extended analytical expression for notch specimens. Furthermore, the SED equation is rewritten as the following form from Eqn. 3:

$$
\Delta \bar{W}=\frac{\Delta \sigma_{n}^{2}}{E}\left[e_{1} k_{1}^{2}\left(\frac{t}{R_{0}}\right)^{2\left(1-\lambda_{1}\right)}+e_{2} k_{2}^{2}\left(\frac{t}{R_{0}}\right)^{2\left(1-\lambda_{2}\right)}\right]
$$


It should be noted that the $\Delta K_{\text {root }}^{N}$ stands for the simplified form of mode I notch stress intensity factor. In order to calculate the NSIFs and SED by EFM method, Meneghetti [20] connects the peak stress with these results to obtain closed-form expression of NSIF and averaged SED values for different modes, which are written as follows:

$$
\begin{gathered}
K_{F E}^{*}=\frac{K_{1}^{N}}{\Delta \sigma_{\theta \theta, \theta=0, \text { peak }} \cdot d^{1-\lambda_{1}}} \cong 1.38 \\
K_{F E}^{*}=\frac{K_{2}^{N}}{\Delta \tau_{r \theta, \theta=0, \text { peak }} \cdot d^{1-\lambda_{2}}} \cong 3.38
\end{gathered}
$$

where $\mathrm{d}$ is the mean finite element size. $\Delta \sigma_{\theta \theta, \theta=0 \text {, peak }}$ and $\Delta \tau_{r \theta, \theta=0 \text {, peak }}$ are the stress results under polar coordination from FE analysis. The $K_{i}^{N}$ values can be obtained from numerical results using very refined FE mesh patterns. Finally, SED values can be deduced by the PSM equation, which is shown as follows:

$$
\Delta \bar{W}=\left(\frac{e_{1}}{E}\left[K_{F E}^{*} \cdot \Delta \sigma_{\theta \theta, \theta=0, \text { peak }} \cdot\left(\frac{d}{R_{0}}\right)^{1-\lambda_{1}}\right]^{2}+\frac{e_{2}}{E}\left[K_{F E}^{* *} \cdot \Delta \tau_{r \theta, \theta=0, \text { peak }} \cdot\left(\frac{d}{R_{0}}\right)^{1-\lambda_{2}}\right]^{2}\right)=\frac{1-v^{2}}{2 E} \Delta \sigma_{e q, \text { peak }}^{2}
$$

The equivalent peak stress can be obtained from the following equation:

$$
\Delta \sigma_{e q, \text { peak }}=\sqrt{c_{w} \cdot\left(f_{m 1}^{2} \cdot \Delta \sigma_{\theta \theta, \theta=0, \text { peak }}^{2}+f_{w 2}^{2} \cdot \Delta \tau_{r \theta, \theta=0, \text { peak }}^{2}\right)}
$$

where $f_{w 1}$ and $f_{w 2}$ are induced according to element size and the corresponding control volume for SED evaluation. It should be noted that the relationship between $\Delta \sigma_{\text {peak }}$ and $\Delta \sigma_{\text {eq,peak }}$ for as-welded joints can be simplified by a correction parameter $f_{w}$, which is shown as follows:

$$
f_{w} \cdot \Delta \sigma_{\text {peak }}=\Delta \sigma_{\text {eq, peak }}
$$

For the notch opening angle $2 \alpha=135^{\circ}$ and the average FE size $d=0.5 \mathrm{~mm}$, the parameter $f_{w}$ is obtained as 1.064 . If the SED values are determined from NSIF analytical solutions, the PSM values can be calculated from Eqn. 9.

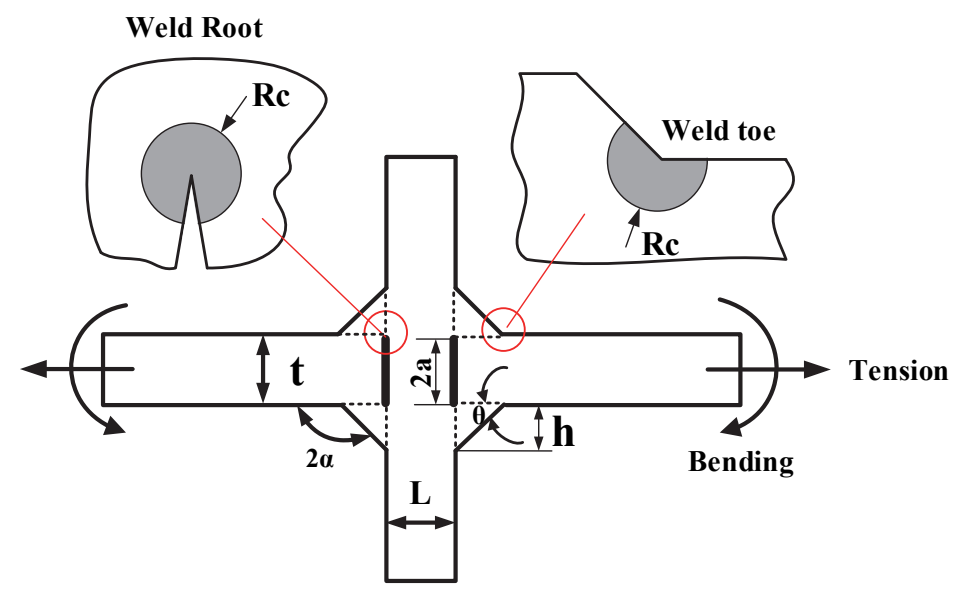

Figure 1: Geometry of cruciform welded joints and corresponding SED geometry illustration. 


\section{THE EXTENDED ANALYTICAL EQUATION BASED ON SIFS}

\section{Extension of analytical solutions}

onsidering the comprehensive effects of joints geometry on the non-dimensional parameters $k_{\mathrm{i}}$, we can deduce the analytical equations from these results via least square fitting methods. The non-dimensional parameters $k_{\mathrm{i}}$ analytical solutions of NSIFs at weld toe in non-load-carrying cruciform joints under pure tension were proposed by Lazzarin et al. [5] and Atzori et al. [23], which are shown as follows:

$$
\begin{aligned}
& k_{1}=1.212+0.495 e^{-0.985(2 b / t)}-1.259 e^{-1.12(2 b / t)-0.485\left(t^{\prime} / t\right)} \\
& k_{2}=0.508-0.797 e^{-1.959(2 b / t)}+2.723 e^{-1.126(2 b / t)-0.769\left(t^{\prime} / t\right)}
\end{aligned}
$$

Similar to the expression of $k_{\mathrm{i}}$ mentioned above, the equations of $k_{\mathrm{i}}$ for LCWJ considering the penetration effect under pure tension and bending loadings can be expressed as the following form:

$$
k_{i}=\left[A_{i}+B_{i} \cdot e^{\alpha_{i}(b / t)}+C_{i} \cdot e^{\beta_{i}(b / t)+\gamma_{i}(p / t)}\right]^{2}
$$

The numerical analysis of LCWJ under different loading conditions demonstrate local geometry imposes negligible effect on the strain energy density, as also reflects in Eqn. 6, which cancel the effect of the attachment plate thickness (L), while incorporates the effects of weld length (h) and penetration length (p). Finally, the $k_{\mathrm{i}}$ equations of weld toe and weld root under different loading conditions from the Eqn. 14 becomes:

For weld toe:

$$
\begin{array}{ll}
\text { Tension: } & k_{1}^{\text {toe, tension }}=1.204-1.284 \cdot e^{-3.691(b / t)}+6.8 \cdot e^{-3.177(b / t)-4.707(p / t)} \\
\text { Bending: } & k_{1}^{\text {toe,bending }}=0.8681+0.6158 \cdot e^{-4.892(b / t)}+2.563 \cdot e^{-7.763(b / t)-22.41(p / t)}
\end{array}
$$

For weld root:

$$
\begin{array}{ll}
\text { Tension: } & k_{1}^{\text {root }, \text { tension }}=0.2553-7.732 \cdot e^{-1.414(b / t)}+9.287 \cdot e^{-1.414(b / t)-0.3516(p / t)} \\
\text { Bending: } & k_{1}^{\text {root, bending }}=0.056+0.2706 \cdot e^{-1.762(b / t)}+0.6201 \cdot e^{-4.556(b / t)-7.304(p / t)}
\end{array}
$$

Based on these extension equations, the NSIF and SED values at weld toe and weld root in LCWJ can be simply estimated without some FE analysis.

\section{EXPERIMENTAL VERIFICATION}

I $\mathrm{n}$ this section, the experiments data were used to verify the proposed analytical solutions. High cycle fatigue experiments of load-carrying cruciform welded joints were performed on a $250 \mathrm{KN}$ electro-hydraulic servo testing system MTS 809 with a loading-control condition. Fig. 3 illustrates the procedure of specimens processing and fatigue tests. Two panels of $10 \mathrm{CrNi} 3 \mathrm{MoV}$ steel were fabricated in Fig. 3(a). Each panel was cut up into LCWJ specimens of $35 \mathrm{~mm}$ width by wire-electrode method, as shown in Fig. 3(b). This steel yield stress is about 693MPa. The nominal stress range of $100-200 \mathrm{MPa}$ was tested with a stress ratio $(\mathrm{R}=0.1)$ and loading frequency between 5 and $15 \mathrm{~Hz}$. More test details are described in Ref. [10]. 


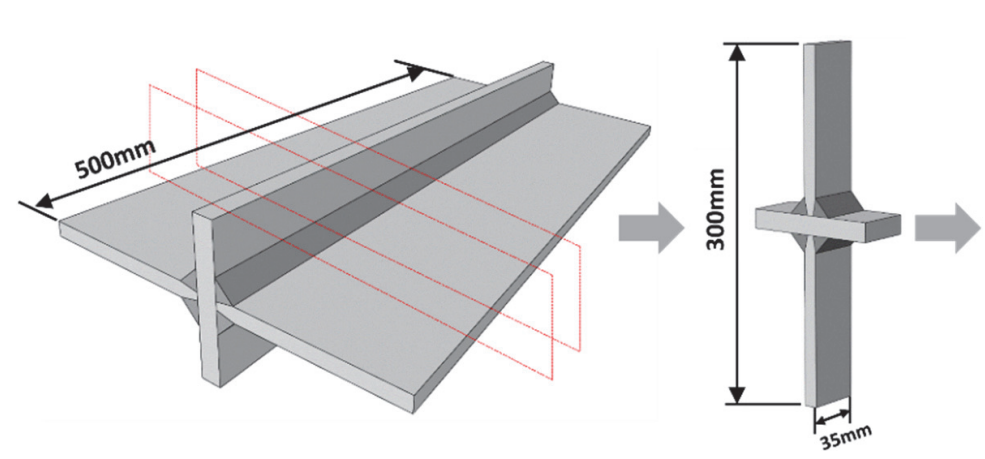

(a) Cruciform joints plate (b) Cruciform joints specimens

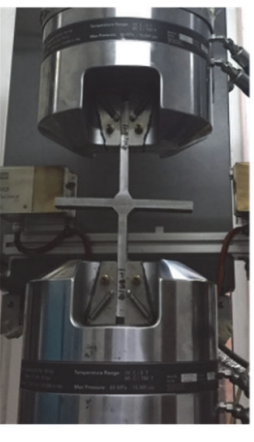

(c) Fatigue tests

Figure 3: Load-carrying cruciform plate/joints specimen sizes and fatigue tests[10].

\begin{tabular}{|c|c|c|c|c|c|c|c|}
\hline Specimens & $\begin{array}{l}\text { Stress range } \\
(\mathrm{MPa})\end{array}$ & Fatigue life & $\begin{array}{l}\text { Fracture } \\
\text { location }\end{array}$ & Specimens & $\begin{array}{l}\text { Stress range } \\
(\mathrm{MPa})\end{array}$ & Fatigue life & $\begin{array}{l}\text { Fracture } \\
\text { location }\end{array}$ \\
\hline Sp1 & 400 & 21500 & Weld toe & Sp13 & 120 & 429300 & Weld toe \\
\hline $\mathrm{Sp} 2$ & 360 & 37800 & Weld toe & Sp14 & 160 & 157400 & Weld toe \\
\hline Sp4 & 280 & 56580 & Weld toe & Sp16 & 320 & 73200 & Weld toe \\
\hline Sp5 & 240 & 129600 & Weld toe & Sp17 & 305 & 28700 & Weld toe \\
\hline Sp6 & 200 & 224700 & Weld toe & Sp18 & 305 & 53500 & Weld toe \\
\hline $\mathrm{Sp} 7$ & 240 & 327400 & Weld toe & Sp19 & 100 & 320500 & Weld root \\
\hline Sp8 & 400 & 15200 & Weld toe & $\mathrm{Sp} 20$ & 120 & 184500 & Weld root \\
\hline Sp9 & 360 & 47000 & Weld toe & $\mathrm{Sp} 21$ & 120 & 156900 & Weld root \\
\hline Sp10 & 280 & 160700 & Weld toe & Sp22 & 150 & 41400 & Weld root \\
\hline Sp11 & 180 & 95000 & Weld toe & $\mathrm{Sp} 23$ & 150 & 54190 & Weld root \\
\hline Sp12 & 150 & 204100 & Weld toe & $\mathrm{Sp} 24$ & 180 & 75450 & Weld root \\
\hline Specimens & $\begin{array}{l}\text { Stress range } \\
(\mathrm{MPa})\end{array}$ & Fatigue life & $\begin{array}{l}\text { Fracture } \\
\text { location }\end{array}$ & Specimens & $\begin{array}{c}\text { Stress range } \\
(\mathrm{MPa})\end{array}$ & Fatigue life & $\begin{array}{l}\text { Fracture } \\
\text { location }\end{array}$ \\
\hline Q345-Sp1 & 130 & 214500 & Weld toe & Q345-Sp14 & 90 & 608738 & Weld toe \\
\hline Q345-Sp3 & 130 & 206234 & Weld root & Q345-Sp16 & 80 & 256961 & Weld root \\
\hline Q345-Sp4 & 120 & 602991 & Weld toe & Q345-Sp17 & 80 & 328896 & Weld toe \\
\hline Q345-Sp5 & 120 & 460568 & Weld toe & Q345-Sp18 & 80 & 294796 & Weld root \\
\hline Q345-Sp6 & 120 & 323194 & Weld toe & Q345-Sp19 & 80 & 810030 & Weld toe \\
\hline Q345-Sp7 & 120 & 343144 & Weld root & Q345-Sp20 & 80 & 552986 & Weld toe \\
\hline Q345-Sp8 & 110 & 482628 & Weld root & Q345-Sp21 & 70 & 962772 & Weld toe \\
\hline Q345-Sp9 & 110 & 523176 & Weld toe & Q345-Sp22 & 70 & 1488320 & Weld toe \\
\hline Q345-Sp10 & 110 & 602503 & Weld toe & Q345-Sp23 & 70 & 1088900 & Weld root \\
\hline Q345-Sp11 & 100 & 548100 & Weld root & Q345-Sp24 & 60 & 677008 & Weld root \\
\hline Q345-Sp12 & 100 & 674549 & Weld root & Q345-Sp25 & 60 & 2296250 & Weld root \\
\hline Q345-Sp13 & 90 & 632400 & Weld root & Q345-Sp26 & 60 & 2085860 & Weld root \\
\hline Specimens & $\begin{array}{l}\text { Stress range } \\
(\mathrm{MPa})\end{array}$ & Fatigue life & $\begin{array}{l}\text { Fracture } \\
\text { location }\end{array}$ & Specimens & $\begin{array}{l}\text { Stress range } \\
(\mathrm{MPa})\end{array}$ & Fatigue life & $\begin{array}{l}\text { Fracture } \\
\text { location }\end{array}$ \\
\hline AISI 304L-Sp1 & 260 & 438000 & Weld root & AISI 304L-Sp8 & 170 & 315000 & Weld root \\
\hline AISI 304L-Sp2 & 230 & 744000 & Weld root & AISI 304L-Sp9 & 150 & 1100000 & Weld root \\
\hline AISI 304L-Sp3 & 210 & 1090000 & Weld root & AISI 304L-Sp10 & 130 & 1980000 & Weld root \\
\hline AISI 304L-Sp6 & 150 & 1840000 & Weld root & AISI 304L-Sp13 & 110 & 983000 & Weld root \\
\hline AISI 304L-Sp7 & 190 & 227000 & Weld root & & & & \\
\hline
\end{tabular}

Table 1: Fatigue test results of 10CrNi3MoV[10], Q345Qd [15] and AISI 304L [16] steel LCWJ.

Before fatigue tests, the LCWJ geometrical profile obtained by image scanner were measured by CAD software. 24 specimens in total were measured and tested. The specimens with zero penetration at weld root is processed by wireelectrode method. The fatigue test data and fatigue failure locations were summarized in Tab. 1. Due to the difference of weld penetration in LCWJ, the fatigue failure modes were different. On the other hand, the fatigue test data of Q345qD and AISI 304L steel LCWJ from $[15,16]$ has been collected for the analysis in this study, which are shown in Tab. 1. 
All the fatigue data are plotted in Fig. 4 in the form of nominal stress ranges $\left(\Delta \sigma_{n o m}\right)$. In IIW standard, the FAT of weld toe and weld root in LCWJ are given as 63 and 36, respectively. The slope of these lines is fixed as 3 in terms of steel. For the $10 \mathrm{CrNi} 3 \mathrm{MoV}$ steel, the results agree well with the FAT63 and FAT36 for the weld toe and weld root, respectively. However, the Q345qD LCWJ fatigue data in Ref. 15 show lower fatigue strength for weld toe failure. It demonstrates that the LCWJs of Q345qD steel are undergrad. Additionally, the LCWJ made by AISI 304 stainless steel were all failure at weld root. Meanwhile, Fig. 4 compares the experimental data relevant to LCWJ made of 10CrNi3MoV steel with the scatter band suggested to design steel welded joints against fatigue. On the other hand, the proposal fatigue design standards based on SED approaches for uniaxial loading by Lazzarin [25] was adopted here. This design scatter bond was proposed by fitting approximately 200 experimental data taken from literatures. Fig. 5 shows the NSIFs against fatigue life, and the results demonstrate that most of the experimental data are agreed with the NSIF design scatter bonds [6] for weld toe and weld root respectively. However, it cannot combine these data into a same scatter bond due to the unit's inconsistency of NSIFs for weld toe and weld root failure. Fig. 6 shows fatigue life assessment by SED for these experimental data. The fatigue strength expressed by averaged strain energy density is $\Delta \mathrm{W} 50 \%=0.015 \mathrm{~N} \mathrm{~mm} / \mathrm{mm}^{3}$, and the inverse slope of the design scatter band is 1.5. A good agreement between theoretical estimations based on SED extended analytical solutions has been obtained for weld toe and weld root failure. Similarly, most of these data are located in the design scatter band. Regards of the fatigue failure criterion from SED method, it shows clearly that the SED criterion boundary can be used to separate the failure mode from the weld geometry in LCWJ, see Fig. 6. These results are compared with the scatter band proposed for steel welded joints, as shown in Fig. 6 and Fig. 7. These design scatter bands reported in Fig. 7 based on PSM has been defined by taking the endurable stress range at 5 million and 2 million cycles. A good agreement between theoretical estimations for PSM $\left(\Delta \sigma_{\text {peak }}\right)$ and experimental data has been obtained for most fatigue test data under tension loading.

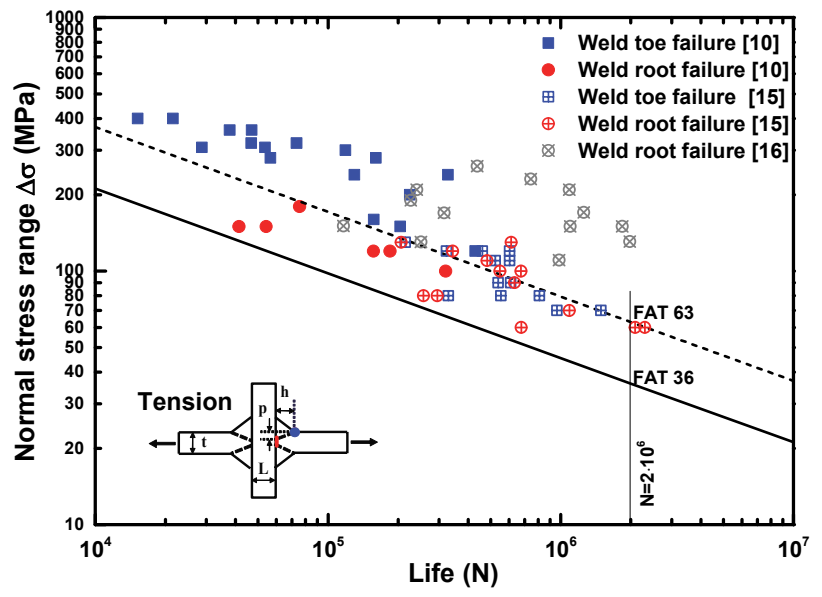

Figure 4: Fatigue test results of $10 \mathrm{CrNi} 3 \mathrm{MoV} \mathrm{LCWJ}$ expressed in terms of nominal stress range.

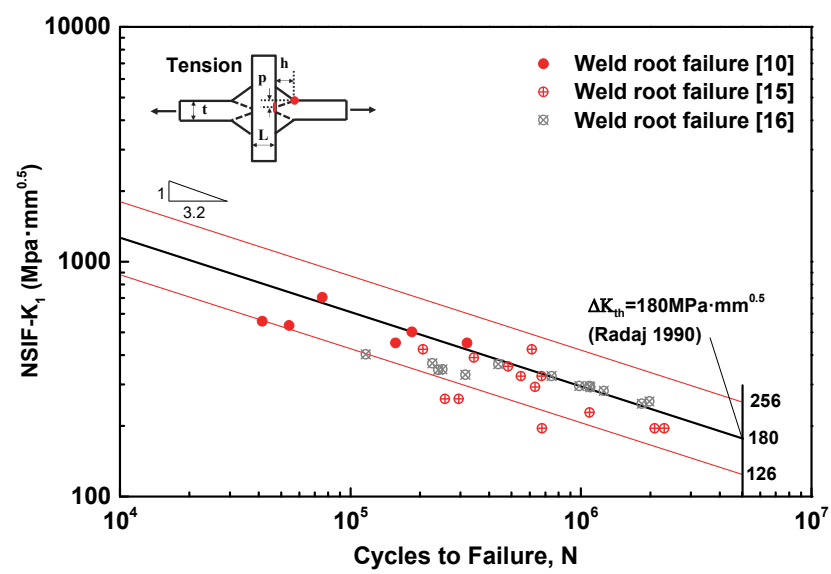

Figure 5: Fatigue test results of $10 \mathrm{CrNi} 3 \mathrm{MoV} \mathrm{LCWJ}$ according to notch stress intensity factors. 


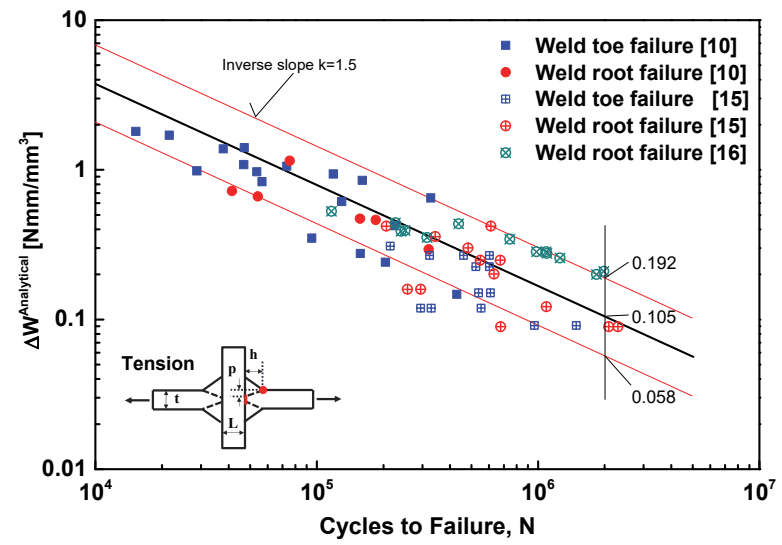

Figure 6: Fatigue test results of $10 \mathrm{CrNi3MoV} \mathrm{LCWJ} \mathrm{according} \mathrm{to} \mathrm{averaged} \mathrm{strain} \mathrm{energy} \mathrm{density} \Delta \mathrm{W}$.

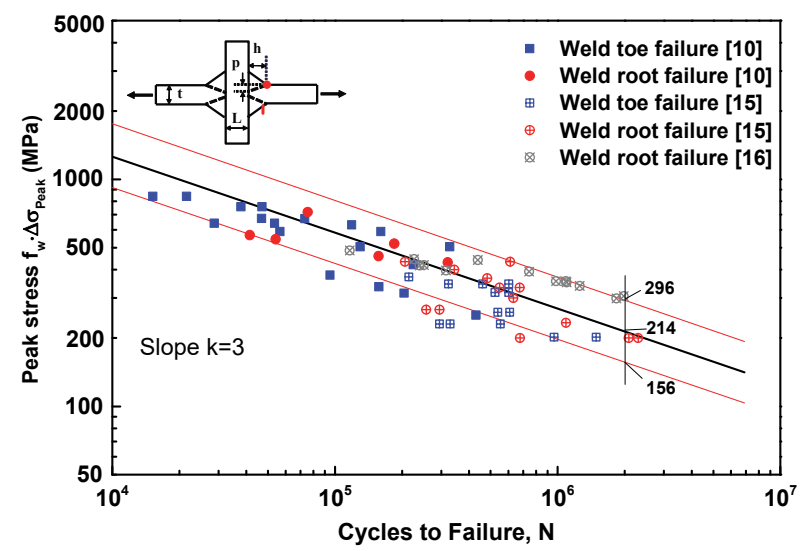

Figure 7: Fatigue test results of $10 \mathrm{CrNi} 3 \mathrm{MoV}$ and $\mathrm{LCWJ}$ according to peak stress methods.

\section{CONCLUSION}

he analytical equations at weld toe and weld root under tension and bending loading in LCWJ were extended to estimate the SED values on the basis of NSIFs. The different geometric factors of LCWJ including incomplete penetration length were incorporated into these analytical formulations. These analytical solutions were verified by the classical notch stress intensity factors from the finite element results. For the sake of extended analytical solutions, the fatigue life assessment of the investigated outcomes of 10CrNi3MoV, Q345qD and AISI 304L steel LCWJs was conducted and it further validates the feasibility of these analytical solutions by local approaches, such as NSIFs, SED, and PSM.

All fatigue data is recalculated by the parameters of notch stress intensity factors and peak stress according to extended analytical solutions for weld toe and weld root failure in LCWJ. This synthesis was verified in the corresponding design scatter bands.

\section{REFERENCES}

[1] Radaj, D. (1996). Review of fatigue strength assessment of nonwelded and welded structures based on local parameters, Int. J. Fatigue 18, pp.153-170.

[2] Hobbacher, A.F. (2016). Fatigue Design of Welded Joints and Components(Second Edition), IIW document IIW2259-2215.

[3] Dong, P. (2001). A structural stress definition and numerical implementation for fatigue analysis of welded joints, Int. J. Fatigue 23, pp. 865-876. 
[4] Atzori, B., Lazzarin, P. and Meneghetti, G. (2008). Fatigue strength assessment of welded joints: From the integration of Paris' law to a synthesis based on the notch stress intensity factors of the uncracked geometries, Eng. Fract. Mech., 75, pp. 364-378.

[5] Lazzarin, P. and Tovo, R. (1998). A notch intensity factor approach to the stress analysis of welds, Fatigue Fract. Eng. Mater. Struct. 21, pp. 1089-1103.

[6] Lazzarin, P., Berto, F., Gomez, F.J. and Zappalorto, M. (2008). Some advantages derived from the use of the strain energy density over a control volume in fatigue strength assessments of welded joints, Int. J. Fatigue 30, pp. 1345-1357.

[7] Lazzarin, P., Berto, F. and Zappalorto, M. (2010). Rapid calculations of notch stress intensity factors based on averaged strain energy density from coarse meshes: Theoretical bases and applications, Int. J. Fatigue 32, pp. 1559-1567.

[8] Lazzarin, P., Berto, F. and Atzori, B., (2013). A synthesis of data from steel spot welded joints of reduced thickness by means of local SED. Theor Appl Fract Mech., 63, pp. 32-39.

[9] Razavi, S.M.J, Ferro, P., Berto, F. and Torgersen, J. (2017). Fatigue strength of blunt V-notched specimens produced by Selective Laser Melting of Ti-6Al-4V, Theoretical and Applied Fracture Mechanics 87.

[10] Song, W. and Liu, X. (2018). Fatigue assessment of steel load-carrying cruciform welded joints by means of local approaches. Fatigue Fract. Eng. Mater. Struct, 41.

[11] Meneghetti, G. (2008). The peak stress method applied to fatigue assessments of steel and aluminium fillet-welded joints subjected to mode I loading, Fatigue Fract. Eng. Mater. Struct. 31, pp. 346-369.

[12] Meneghetti, G., Marchi, A. De and Campagnolo, A. (2016). Assessment of root failures in tube-to-flange steel welded joints under torsional loading according to the Peak Stress Method, Theor. Appl. Fract. Mech. 83, pp. 19-30.

[13] Nykänen, T., Li, X., Björk, T. and Marquis, G., (2005). A parametric fracture mechanics study of welded joints with toe cracks and lack of penetration, Eng. Fract. Mech. 72, pp. 1580-1609.

[14] Liu, G., Liu, Y. and Huang, Y. (2014). A novel structural stress approach for multiaxial fatigue strength assessment of welded joints, Int. J. Fatigue 63, pp. 171-182.

[15] Zong, L., Shi, G., Wang, Y.-Q., Yan, J.-B. and Ding Y. (2017). Investigation on fatigue behaviour of load-carrying fillet welded joints based on mix-mode crack propagation analysis, Archives of Civil and Mechanical Engineering 17, pp. 677-686.

[16] Singh, P. J., Achar, D. R. G., Guha, B. and Nordberg, H. (2003). Fatigue life prediction of gas tungsten arc welded AISI 304L cruciform joints with different LOP sizes, International Journal of Fatigue, 25, pp. 1-7.

[17] Xing, S., Dong, P. and Threstha, A. (2016). Analysis of fatigue failure mode transition in load-carrying fillet-welded connections, Marine Structures, 46, pp. 102-126.

[18] Lazzarin, P., Berto, F., Zappalorto, M. and Meneghetti, G. (2009). Practical application of the N-sif approach in fatigue strength assessment of welded joints, Welding in the World, 53.

[19] Feng, L. and Qian X. (2017). A hot-spot energy indicator for welded plate connections under cyclic axial loading and bending, Eng. Struct. 147, pp. 598-612.

[20] Saiprasertkit, K., Hanji, T. and Miki, C. (2012). Fatigue strength assessment of load-carrying cruciform joints with material mismatching in low- and high-cycle fatigue regions based on the effective notch concept, Int. J. Fatigue 40, pp. 120-128.

[21] Gross, B. and Mendelson, A. (1972). Plane elastostatic analysis of V-notched plates, Int. J. Fract.Mech. 8, pp. $267-276$.

[22] Lazzarin, P. and Zambardi, R. (2001). A finite-volume-energy based approach to predict the static and fatigue behavior of components with sharp V-shaped notches, Int. J. Fract. 112, pp. 275-298.

[23] Meneghetti, G., Marini, D. and Babini, V. (2016). Fatigue assessment of weld toe and weld root failures in steel welded joints according to the peak stress method, Welding in the World, 60, pp. 559-572.

[24] Atzori, B., Lazzarin, P. and, Tovo R. (1999). Stress field parameters to predict the fatigue strength of notched components, J. Strain Anal. Eng. Des. 34, pp. 437-453.

[25] Lazzarin P., Livieri P., Berto F. and Zappalorto, M. (2008). Local strain energy density and fatigue strength of welded joints under uniaxial and multiaxial loading, Eng. Fract. Mech. 75, pp. 1875-1889. 